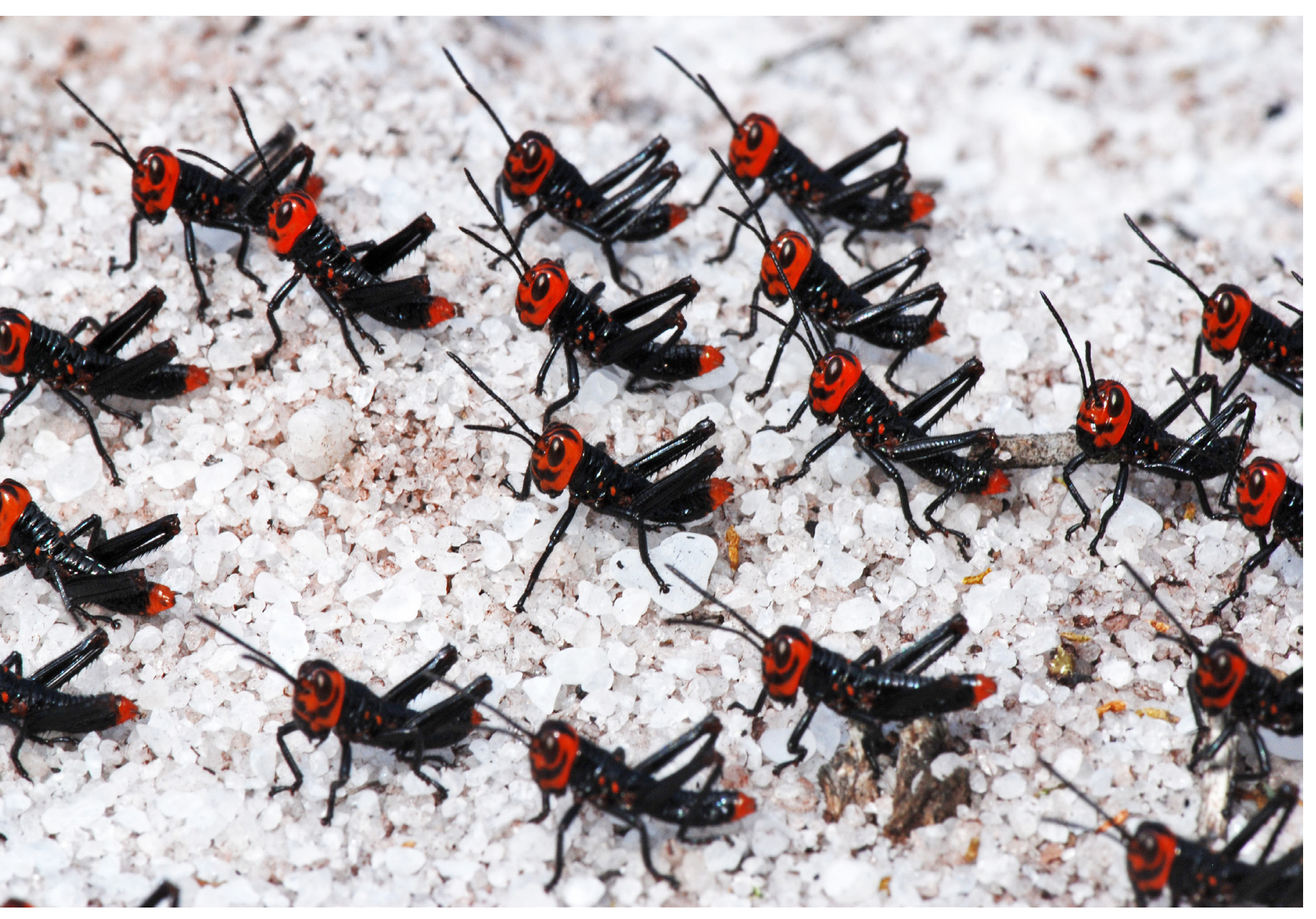




\title{
Pedagogia Hospitalar: Um Aluno, um Caso
}

\author{
Pedagogy Inside The Hospital: one student, one Case
}

\section{Resumo}

O objetivo deste estudo é compreender a importância da educação para casos específicos de crianças e adolescentes hospitalizados para o seu desenvolvimento e o modo como a pedagogia, no caso os professores, deve se adaptar às condições diversas que encontra nesses casos. Através de uma pesquisa qualitativa, com um roteiro estruturado, as observações foram realizadas em um ambiente hospitalar, voltado para um caso específico, contendo inúmeras necessidades educacionais especiais. Neste artigo são mencionadas quatro diferentes categorias que se encontram presentes dentro da classe hospitalar e estão relacionadas às questões do caso pesquisado, sendo elas a complexidade de um processo educacional de um aluno hospitalizado, múltiplas visões sobre a importância da educação nos hospitais, os saberes e métodos dos professores e as articulações entre família, professor, hospital e aluno.

Palavras-chave: Pedagogia Hospitalar; Necessidades Educacionais Especiais; Superação de Limitações.

Caroline Pereira Ribeiro

Marcela de Menezes Dal Col ${ }^{*}$ Maria Rita Klein Stein

Universidade Federal do Espírito Santo (UFES)

Email:marcela.dalcol@hotmail.com 


\section{Abstract}

The objective of this study is to understand the importance of education for specifics cases of hospitalized children and teens for their development and the way that pedagogy, specially the teacher, have to adapt to the differents conditions that exist in this cases. Based on a qualitative study, with a structured script, the observation was executed in a hospital, with a specific case, that had specials educational necessities. In this study are mentioned four differents categories that take place inside the hospital classroom and are related to issues of the researched case, being them the complexity of the educational process of a hospitalized student, multiples visions of the importance of education inside the hospital, the knowledge and methods of teachers and articulations between family, teacher, student and hospital.

Keywords: Pedagogy Inside the Hospital, Specials Educational Necessities, Overcome of Limits. 


\section{INTRODUÇÃO}

Percebe-se, apesar do que muitos acreditam e, por isso desvalorizam, que até crianças que têm limitações extremas e que podem nem conseguir aprender a ler e a escrever, como crianças com deficiência motoras e mentais, necessitam da educação. Os efeitos da educação vão desde o desenvolvimento da criança como pessoa e como cidadão até questões psicológicas. A pesquisa e suas observações, nesse contexto, têm como objetivo compreender a importância da educação para casos específicos de crianças e adolescentes hospitalizados, para o seu desenvolvimento e o modo como a pedagogia, no caso os professores, deve se adaptar às condições diversas que encontra nesses casos. Realizamos este trabalho para compreender o que acontece dentro dos hospitais com relação à educação de crianças que têm a necessidade de habitá-lo. Por conseguinte, estudamos um caso de um menino que mora há seis anos no Hospital do município de Domingos Martins.

Para iniciar a pesquisa, é preciso reconhecer que a saúde e a educação podem ser de certo modo interligadas, e como se refere Walkíria de Assis (2009), os profissionais dessas áreas, tanto os médicos como os professores, têm "o compromisso com o crescimento humano em todos os seus aspectos”. O efeito psicológico principal da educação para crianças hospitalizadas, que Silvia Moreira Trugilho (2003) expressa em seus estudos sobre pedagogia hospitalar como "otimismo trágico", está relacionado em grande parte a uma força para enfrentar as dificuldade, no caso a doença. É na educação que muitas crianças hospitalizadas por longo período e abaladas pela doença encontram um sentido para a existência.

Dentro desse contexto, existe a necessidade séria de adaptação por parte dos profissionais da educação envolvidos com educação hospitalar. Como Lima (2010) menciona em seus estudos, o professor do hospital deve apresentar, além dos conhecimentos que todo professor necessita, os conhecimentos específicos sobre o meio hospitalar em suas exigências. A pedagogia hospitalar, porém, ainda não é em muito desenvolvida. Paula (2015), a respeito da educação popular e pedagogia hospitalar, demonstra que esse ramo da educação ainda é profissionalmente muito desconhecido em nosso país. No entanto, como já visto anteriormente, ela é de extrema importância. A educação, nesse sentido, envolve uma questão muito mais ampla que os aprendizados básicos.

$\mathrm{Na}$ instituição visitada, por exemplo, teremos contato com os métodos aplicados pela professora, em relação a uma criança, um menino, que não fala e nem se move muito; o que ele consegue fazer é digitar, e se comunicar por leitura labial. Vimos como funcionava o trabalho pedagógico, a relação da mãe com a professora e o convívio com as pessoas dentro do hospital. É preciso demonstrar a necessidade da disponibilidade de profissionais para esse tipo de projeto, a atuação de professores e de projetos de pedagogia hospitalar nos hospitais, o que é ainda muito raro. As crianças, o professor, a família e a sociedade, no caso o hospital que representa grande parte do seu meio social, completam um quadro que precisa ser analisado e compreendido para o aprimoramento futuro de profissionais. 


\section{METODOLOGIA}

O trabalho, caracterizado como um estudo de caso, desenvolveu uma metodologia de pesquisa qualitativa, pois tem como foco o aprofundamento de um caso específico, conforme descrito acima. Ao longo da pesquisa, foram apresentados os assuntos que envolviam a temática, a forma de realização e procedimentos empregados para obter os resultados positivos desejados.

A primeira etapa foi a escolha e o reconhecimento do local. A visita ao hospital foi realizada apenas para conhecer os sujeitos envolvidos no caso e explicar o objetivo do trabalho. Esta etapa foi facilitada pois a instituição hospitalar estava interessada amplamente na pesquisa. $\mathrm{O}$ apoio e a receptividade foi um ponto forte, sendo manifestada tanto por parte do hospital, representado pela assistente social, como por parte da família, no caso a mãe que mora com o paciente no hospital, e da professora, que trabalha com ele há um tempo.

Após conhecer mais o caso do menino, o grupo preparou um roteiro para a entrevista, com perguntas, temas e dúvidas a serem abordadas de forma estruturada. As etapas de observação das relações entre os sujeitos que envolviam o processo educacional do aluno hospitalizado e das aulas realizadas pela professora, aconteceram nas visitas seguintes. As entrevistas com a mãe, professora e assistente social, além de uma entrevista virtual com o aluno, foram executadas simultaneamente às observações, momento em que foram colhidos alguns relatos. A partir do ponto de vistas dos entrevistados, se conheceu o contexto em que o aluno se encontra para melhor compreender a complexidade que envolve seu processo educacional. Posteriormente, na realidade não propositalmente, o grupo realizou uma atividade com aluno de Contação de Histórias que foi também muito produtiva, em que se observou a educação a partir de um último ponto de vista, dos próprios realizadores da pesquisa, de maneira ativa.

De acordo com as respostas obtidas nas entrevistas, permitiu-se, através de um diálogo, o máximo de liberdade possível para os sujeitos envolvidos. Portanto, com essa abertura, espera-se que esta pesquisa atinja o seu objetivo, contribuindo para um resultado satisfatório.

\section{Pedagogia Hospitalar: A Educação em uma Nova Dimensão}

1. A Importância da Educação Hospitalar

No contexto da pedagogia hospitalar, é importante considerar a relação entre a saúde e a educação. As duas apresentam objetivos parecidos, que buscam desenvolver o indivíduo e remediar males, sejam eles do corpo ou da alma. A condição de ser ou estar doente não é uma tarefa fácil de ser enfrentada, especialmente para uma criança, uma vez que:

[...] Uma enfermidade pode produzir diferentes manifestações nos pacientes, pois cada um tem a sua história pessoal, o modo próprio de relacionar-se com seu meio sociocultural, no entanto, o sofrimento enfrentado 
pelo indivíduo enfermo desgasta a todos que com ele convivem. (Assis, 2009, p.35).

A classe hospitalar na educação é voltada para um conhecimento médico e psicológico, pois existe uma complexidade e vários desafios dentro do ambiente hospitalar. Nesse contexto, os profissionais de saúde e de educação podem e devem contribuir para evitar esses males conjuntamente, através de atitudes para conhecer e dialogar com seus alunos ou pacientes. A criança precisa se sentir capaz de fazer algo para a sua melhora seja no corpo, seja na alma. Uma melhora na autoestima e na esperança provoca um aumento na imunidade. A criança se alimenta melhor, dorme melhor, contribui para os procedimentos médicos. O benefício, dessa maneira, pode ser encontrado tanto na saúde, como na educação.

A educação desenvolve uma grande importância dentro da classe hospitalar, pois segundo Trugilho (Ibid.), a hospitalização afasta o paciente do seu meio de convívio familiar e social, e então passa a ser influenciado pelo ambiente onde ele se encontra, deixando marcas profundas no seu desenvolvimento. As influências que são adquiridas em um ambiente hospitalar, na maioria das vezes, atingem a parte emocional do paciente, como o sentimento de fracasso, de desespero, de sofrimento e de solidão.

A angústia também está presente na vida cotidiana dentro do hospital, pois estando internado, o paciente passa a se sentir incapaz de batalhar pela sua própria vida e diariamente é ameaçado pelo medo da morte, pois a falta de esperança pela própria vida é muito presente em um ambiente hospitalar. Exatamente neste contexto, é possível identificar o papel da escolarização. Diante um momento de dor e sofrimento vivido por pacientes, é preciso existir a coragem de enfrentar tudo o que é desafiador e transformar toda a dor em vontade e alegria de viver.

Para Trugilho (2003), a capacidade de vencer a dor com esperança e transformar a tragédia em uma conquista, é o que vem a ser o otimismo trágico. Mesmo diante de um tratamento rígido e doloroso, segundo a autora, o paciente precisa obter algumas virtudes, como a coragem, o humor, a amizade, o companheirismo e compaixão. Ela menciona o humor como uma forma de ultrapassar obstáculos existentes no meio da batalha. Sem o humor, a capacidade de suportar o momento trágico diminui. Sobre o humor Trugilho acrescenta "que ele emerge como virtude que possibilita ao homem enfrentar, suportar e transcender a situação de tragicidade. Sem esta virtude, o sofrimento se torna ainda maior e a capacidade de enfrentá-lo fica bastante reduzida (p.202)".

É através do otimismo trágico que o paciente encontra uma forma de investir na própria vida, ter grande vontade de viver, mesmo se deparando com todas as circunstâncias negativas existentes ao seu redor. É este otimismo que desperta, principalmente, o desejo de superar todos os obstáculos e de não sucumbir facilmente aos seus problemas.

A educação tem um papel importante para promover a dignidade, para 
superar a doença e, não menos importante, para conquistar uma liberdade que se encontra oculta por trás das paredes do hospital. Além disso, a educação contribui para se pensar em um futuro melhor para todos, deixando de lado a finitude presente no âmbito hospitalar e começa um processo de transformação do sentimento negativo em algo positivo, como a esperança de viver. Trugilho afirma que:

As crianças e os adolescentes, mesmo diante de uma doença crônica e da possibilidade da morte, apegam-se à escolaridade, transformando-a no aliado que auxiliará a trilhar o árduo caminho em direção de um sentido a realizar na vida futura. Este sentido projetado de futuro funciona como um combustível vital, renovando forças e coragem, sem as quais a entrega ao inimigo (doença) é fatal, mas com as quais é possivel transpor o sofrimento inevitável. (Ibid., p.206).

Independentemente do tempo de permanência do paciente no ambiente hospitalar, o otimismo trágico é uma forma de superação através de valores existentes na sociedade. Esses valores ajudam o paciente olhar a sua vida além de seu tratamento médico e conhecer o verdadeiro sentido da vida.

Nem todas as crianças e adolescentes hospitalizados e/ou com alguma doença crônica carregam em si esta qualidade do otimismo trágico. Aqueles que não desenvolvem esta habilidade de enfrentamento otimista da situação trágica em que se encontram, dificilmente possuem um sentido a realizar na vida e, assim, a doença torna-se obstáculo intransponível ao qual se entregaram em rendição. (Ibid., 2003, p.210).

O otimismo trágico, juntamente com a educação, é capaz de obter resultados extremamente positivos para o paciente. O encontro com a verdadeira razão de viver é descoberto pelo paciente com a ajuda dos amigos e familiares, através da amizade, afetividade, alegria, sonhos e esperança. Toda essa relação pode levá-lo a obter melhoras em seu tratamento médico, facilitando a cura. Por isso, a escolaridade necessita andar lado a lado com o tratamento médico, promovendo uma troca de benefícios entre ambos.

\section{Formação Docente para Educação Escolar}

Segundo Lima (2010), "refletir sobre o que significa 'ser professor' não é nada inédito nem recente, porém, em todos os momentos de grandes transformações sociais, a escola é colocada em evidência e seus atores em pauta” (p.53). A escola já é um cenário típico para o professor, porém, quando o cenário muda a especialização também se transforma.

Para ser um educador em um ambiente hospitalar, é preciso uma especialização adequada, pois a situação que o docente encontra é totalmente diferente 
de uma sala de aula. A discussão sobre a formação docente não poderia ser menos atual. Em seus estudos sobre os saberes necessários para atuar na educação hospitalar, Lima (Ibid.) menciona que um educador do hospital deve apresentar, além dos conhecimentos que todo professor necessita, os conhecimentos específicos sobre o meio hospitalar em suas exigências, além de uma preparação para a educação de crianças especiais, pois muitas permanecem nos hospitais.

A formação, por outro lado, deve estar muito mais ligada à experiência e ao social, a partir de reflexões que promovam uma formação de educadores durante todo o seu exercício profissional, compartilhando saberes e vivências em contato com o outro:

O profissional de educação, [...] se estiver realmente envolvido em seu trabalho estará, conforme educa, educando-se. Na medida em que colabora para o aperfeiçoamento dos alunos ou de seus pares, estará aperfeiçoando-se em um preparar-se constante para a vivência de seu papel educador. (Ibid., p 57).

Esta formação deve proporcionar situações que possibilitem a reflexão e a conscientização das limitações sociais, culturais e ideológicas da própria profissão docente (GARCIA, apud LIMA, 2010, p.57). A citação de Garcia relata um ponto muito relevante na formação de educares que atuarão em ambientes hospitalares que é "proporcionar situações", assim um professor que acabou a sua graduação e não tem experiência nesse ramo pode de alguma forma realizar seu trabalho com um bom desempenho.

Segundo Lima (Ibid., p.56), "formar-se professor nessa área vai além de as especificidades de uma dada área específica do conhecimento, também significa aprender a ser um mediador entre os conhecimentos e os alunos, o que exige também uma reflexão sobre as limitação e possibilidades do contexto político em que a prática docente ocorre". Além disso, nesse contexto hospitalar assim como em situações escolares em geral, tanto o aluno como o professor estão constantemente se construindo a partir de experiências.

\section{Desafios da Educação Hospitalar}

O acesso à educação e a sua aplicação como direito fundamental são realidades problemáticas no Brasil, devido à situação de grande desigualdade social. A pedagogia hospitalar também se encontra nesse contexto problemático educacional. Considerando que nem todas as crianças têm acesso à escola regular, no caso das crianças enfermas que residem em hospitais, como elas não são consideradas com a devida prioridade, muitas vezes são esquecidas. Os professores se inscrevem para atuar no ambiente hospitalar e, normalmente, não existe qualquer preparação específica e não há obrigatoriedade de atendimento por parte do Estado. Além disso, não se pode ignorar a possibilidade de que esses professores diminuam a fre- 
quência em relação à condição social e econômica da região em que o hospital se encontra, fato que também revela mais reflexos da desigualdade social.

A afetividade está presente em muito desses projetos, mas em alguns a realidade violenta e opressora do lugar em que hospital se encontra é desconsiderada pelo professor. Existem relatos de maus-tratos a crianças enfermas, seja por enfermeiras e médicos, seja pelos próprios professores. Se esta criança já se encontra em uma situação de isolamento e de defasagem, na maioria dos casos, dos estudos, qualquer tipo de violência contra ela é completamente prejudicial à sua educação (PAULA, 2015, p.9).

A mobilização de professores para atuarem nessas áreas é relevante para que se modifique a forma de pensar sobre essa educação, provocando reflexão e levando a que se busque maior envolvimento dos profissionais a respeito da importância desses serviços e da necessidade de aumentar a sua oferta, já que se encontram tão escassos. A pedagogia hospitalar, no entanto, apenas ganhará destaque com incentivos do governo e especializações.

\section{Uma História da Educação}

1. A complexidade de um processo educacional de um aluno hospitalizado

As classes hospitalares existentes apresentam geralmente alunos com doenças similares e, desse modo, limitações similares. Em vários casos, no entanto, as crianças se encontram isoladas e apresentam necessidades diferentes, como é o caso do aluno cuja história inspirou essa pesquisa.

O aluno apresenta uma doença chamada Distrofia Muscular de Duchenne, uma doença hereditária, ou seja, a criança já nasce com a doença. Essa distrofia é uma doença degenerativa. Os músculos dos doentes não possuem uma proteína essencial e, por isso, não se desenvolvem como deveriam. As crianças passam a apresentar, principalmente, problemas na função motora, além de uma fraqueza generalizada que dificulta o aprendizado.

A Distrofia de Duchenne evolui mais rapidamente que todos os outros tipos de distrofia existentes. Sem músculos, as funções cardíacas e respiratórias também começam a apresentar problemas com o tempo. Aos poucos, as crianças perdem a capacidade de andar por volta dos 12 anos. 0 aluno tem 25 anos de idade. Ele já não anda e tem dificuldade para respirar sem um aparelho que produz pressão pulmonar. A sua habilidade de escrita manual também tem se perdido. A fala é difícil, não produz muitos sons. No entanto, a leitura orofacial é facilmente e comumente utilizada por todos de seu convício diário, inclusive pela professora nas aulas.

As complicações nas funções cardiorrespiratórias são as principais causas de morte. Normalmente, os que apresentam essa distrofia não vivem mais que 30 anos. Em todos os relatos, entrevistas e observações não se verificaram quaisquer referências à morte. A esperança e a alegria estavam presentes no ambiente. Ninguém, dentre todos os relacionados ao sujeito que encontramos no contexto hospitalar que visitamos, demonstrou qualquer tipo de pena. Isso, aparentemente, já 
pode ser considerado como fator positivo para que o ambiente de vivência do menino propicie um melhor desenvolvimento.

Como as funções foram se perdendo com o tempo e as limitações foram se modificando, a abordagem no âmbito da educação também sofreu muitas mudanças durante seu processo educacional, o qual foi relatado pela mãe e pela professora. O aluno, em um período inicial, cursava a escola na maior parte como aluno especial, pois necessitava da cadeira de rodas. Com o tempo, no entanto, surgiu a necessidade de ficar no Hospital. A partir desse ponto, iniciou-se uma mobilização. "A assistência social comunicou à escola sobre a presença do sujeito no hospital e a necessidade de acompanhamento escolar" (Professora).

As aulas específicas para o menino sempre foram discutidas com o mesmo. O professor deve sempre levá-lo em consideração. Os resultados, nesses casos, são normalmente mais positivos.

Ele admitiu que não gostava de ler e que nem sabia a tabuada. O método de aula, portanto, foi direcionado inicialmente para incentivá-lo nesses pontos. Ele aprendeu a gostar de ler e chegou até a ler mais que os garotos dentro da escola. Outras professoras também participaram inicialmente, como a educação dele era obrigatória. (Professora).

As complicações e mudanças sempre aparecem, devido à complexidade que uma educação hospitalar geralmente apresenta. A professora foi, já sem a participação das outras professoras, afunilando com o próprio aluno o que era mais importante para o estudo. Esse processo foi de certa maneira influenciado por novas limitações físicas que foram aparecendo.

Em certos momentos ocorreu uma cobrança da superintendência, já que ele estava matriculado no ensino médio, mas não possuía as matérias obrigatórias do currículo escolar. Eles diziam que tinha que ser do jeito deles, mas ninguém sabia a real situação. (Professora).

Nesse sentido, percebe-se uma cobrança sem a consideração necessária. Em geral, as autoridades se apegam demais à questão de conteúdo e das disciplinas curriculares e, muitas vezes, não se adaptam corretamente à especialidade do caso, como revela esta fala: "Porque nós iríamos trabalhar Português e Matemática se ler é tão mais divertido?" (Professora). Para o aluno, a educação só tem utilidade se servir de diversão, além de conhecimento.

\section{Múltiplas visões sobre a importância da educação nos hospitais}

A pedagogia da classe hospitalar atende aos pacientes sem expectativas de vida. Há casos em que até mesmo a família acredita na finitude do paciente e acham desnecessário o ensino escolar, pelo fato de não ter expectativas de vida ou pelo 
paciente não ter oportunidades no mercado de trabalho futuramente. Em relação a isso, a assistente social entrevistada pelo grupo possui um pensamento diferenciado aos dos familiares dos pacientes diagnosticados em geral. Para ela, a escolaridade é sim importante, o ensino vale a pena, a partir do momento em que os pacientes tiverem condições de aprender. Segundo ela, "A educação é uma forma de abrir seus horizontes e criar diversas alternativas de escolhas, para começar a enxergar a realidade de forma diferenciada" (Assistente Social).

Com a mesma linha de pensamento da assistente social entrevistada, TrugiIho (2003) defende que o paciente precisa ter esperanças e lutar cada dia, independentemente dos riscos de vida presentes no tratamento médico. Nunca desistir de adquirir conhecimentos, somente pelo fato de o futuro estar ameaçado, o importante é ter o presente e vivê-lo de maneira marcante.

E, se não houver futuro, há que se realizar algo significativo no presente, deixando na vida sua marca, que mesmo singular e pessoal, poderá revelar que não se viveu em vão. Mesmo se não houver futuro, o presente foi vivido com dignidade. Se a batalha foi vencida pelo inimigo, foi porque este era invencivelmente mais forte e não porque houve entrega, desistência e conformismo. (Ibid., p.207).

Segundo a entrevista escrita realizada com o paciente abordado pelo grupo de pesquisa, a educação é importante pelo ensino e aprendizagem que ele é capaz de adquirir. O que chama a atenção é que esse paciente possui um otimismo trágico, porque diante todas as suas limitações ele revela que o ensino é uma forma de "abrir a porta para o futuro", ou seja, mesmo sem poder sair do leito do hospital algum dia e ter certa finitude, ele tenta superar todos os desafios do cotidiano com positividade. Além de todas as limitações, ao ter esse contato com a educação, mesmo sendo de forma diferenciada da educação escolar, o paciente se sente capacitado assim como qualquer outro aluno da rede de ensino.

Para o trabalho pedagógico hospitalar ser realizado com êxito, é necessário o apoio e o incentivo dos pais e familiares do paciente. Durante a entrevista com a mãe do paciente (foco do grupo), ela disse que a educação para o seu filho é uma forma de ele se sentir socializado com o mundo, a educação faz com ele se sinta igual às outras pessoas com a mesma faixa etária, nem pior, nem melhor.

Trugilho (Ibid.) aborda em seus estudos, a maneira de como a educação pode influenciar no resultado do tratamento médico, trazendo na maioria das vezes, muitos benefícios para a saúde do paciente. A mãe do paciente, durante a entrevista, disse que "tanto o tratamento hospitalar como a educação precisam andar juntos e em harmonia” (Mãe do aluno).

O enfrentamento otimista da doença é fortalecido pela pedagogia no ambiente hospitalar, quando o paciente busca na educação um objetivo a realizar em sua vida. Segundo Silvia: 
Nem todas as crianças e adolescentes hospitalizados e/ou com alguma doença crônica carregam em si esta qualidade do otimismo trágico. Aqueles que não desenvolvem esta habilidade de enfrentamento otimista da situação trágica em que se encontram, dificilmente possuem um sentido a realizar na vida e, assim, a doença torna-se obstáculo intransponível ao qual se entregaram em rendição. (Ibid., p.210)

A professora entrevistada prioriza o direito à educação. Para ela todos têm esse direito, mesmo estando impossibilitados de acessar uma rede de ensino. Então, é preciso garantir o direito da educação respeitando e adaptando-se às circunstâncias e limitações dos alunos e pacientes para garantir uma educação de qualidade. A entrevistada defende que "A pedagogia nos hospitais é importante pelo fato de criar condições e possibilidades de se trabalhar com a educação e assim, especialmente para as crianças, adolescentes e jovens, não acontecer um rompimento dos anos escolares." (Professora).

\section{Professores e Alunos Enfermos: Saberes e Métodos}

Os métodos de aula devem ser aplicados pelo professor da pedagogia hospitalar de forma a obter um melhor aproveitamento do aluno. Segundo a Professora, "os conhecimentos necessários aos professores são aqueles necessários também ao seu trabalho na sala regular de ensino. Para além deste conhecimento é indispensável ao professor compreender o funcionamento deste local, a condição daquela pessoa com quem ele trabalhará".

Nesse ponto muitas vezes a experiência faz uma grande diferença na questão da preparação do professor, pois este está mais preparado para encontrar diferentes condições e adaptar-se a elas. "É claro que é necessário conhecer e ir em busca de métodos conforme a necessidade do estudante. A nossa organização pretende ser um trabalho que considera o aluno, a sua condição e os seus interesses" (Professora). O papel do professor na pedagogia hospitalar é, antes de tudo, adaptar o método de aula para o aluno.

Eu então decidi fazer o certo. O certo que decidimos entre nós, eu, o aluno e sua mãe, é que nós iríamos ler, muito. Só sei que, ele que não gostava de ler, agora eu tenho que pedir permissão para ler uma parte. (Professora).

Pelo método empregado, a aula transformou-se, na verdade, na leitura de um livro. Pode-se analisar a leitura de um livro, nesse ponto, como um processo bem mais amplo. Como relata Verdi, a partir de uma

[...] história conseguimos sentir emoções importantes como: tristeza, raiva irritação, medo, alegria, pavor, impotência, insegurança, etc.; podemos 
descobrir outros lugares, outros tempos, outros jeitos de agir e ser, outras regras, outras éticas, outra ótica.... Desenvolvemos o poder de pensar, duvidar, perguntar, relatar [...], enfim, através das histórias conseguimos embasar questões e atitudes essenciais do ser humano. (Verdi, 2010, p.161).

A tecnologia, nesse contexto hospitalar, também aparece como instrumento fundamental. A mãe do aluno desabafa que "foi graças ao Facebook que ele se interessou por aprender a ler e escrever. No Facebook, a pessoa é obrigada a ter essas habilidades para interagir, senão eu teria que ler e escrever tudo”. Os ambientes virtuais "[...] são capazes de colocar em prática as necessidades que os novos paradigmas educacionais reforçam. São ferramentas de auxílio [...] que não podem prescindir da figura do professor (TORRES; MATOS; BORTOLOZZI, 2010, p.206)". A Professora também destaca que "a tecnologia é um aparador incrível, assim como o livro é". A tecnologia, no entanto, deve ser usada na hora certa e com cuidado.

Dentre as metodologias utilizadas com o aluno, a atividade de Contação de Histórias foi muito produtiva, pois o grupo de pesquisa pôde se tornar participante e não apenas observador. A partir da aplicação dessa atividade, percebeu-se como um momento de descontração e de interação pode fazer grande diferença em todo o clima do ambiente hospitalar e como torna o dia-a-dia de uma criança enferma muito menos cansativo. Portanto, a atitude de todos os envolvidos no cotidiano do aluno e a participação em projetos pedagógicos é imprescindível para uma agradável vivência no Hospital.

\section{Articulações entre Família, Professor, Hospital e Aluno}

Dentro da pedagogia hospitalar, a relação entre professor, aluno, família e hospital é bastante complexa. A participação da família é fundamental, como pode ser observado nesse caso. A professora e a mãe dialogam para elaborar um método de aula mais apropriado para o enfermo. Através de dinâmicas pedagógicas e interação entre família e professor, a criança e o adolescente são auxiliados para dar um diferente significado a esse momento de suas vidas (FONTANA; SALAMUNES, 2010, p.58).

Assim como não se pode separar a criança da família, é impossível separar a criança do ambiente hospitalar no qual vive. Assim, a solução viável para o professor é viabilizar que o familiar e as equipes de saúde se tornem participativos no processo contínuo de aprendizagem da criança (RODACOSKI; FORTE, 2010, p.68).

A partir do início da permanência do paciente no hospital se faz necessária a articulação entre o Hospital, nesse caso representado pela assistente social, com a escola e as professoras que realizarão as aulas no hospital. "O papel dos hospitais é liberar a entrada das escolas e dos educadores" (Mãe). O processo do início e prosseguimento do acompanhamento pedagógico é complicado e lento, mas precisa ser feito com a maior eficiência possível para o benefício do escolar hospitalizado. Para compreender todo esse processo é que se tornam importantes as pesquisas sobre a 
Pedagogia Hospitalar.

Deviam fomentar muito mais os alunos a procurar os hospitais para realizar este tipo de pesquisa, pois é quase inédito. As pesquisas, para nós, servem como formas de conhecimentos, voltadas para a melhoria das instituições. (Assistente social).

Da mesma maneira, o “[...] trabalho pedagógico, neste contexto, é certamente uma perspectiva nova, porém altamente pertinente e necessária, não menos complexa, tanto para o pedagogo como para a equipe hospitalar, hospitalizados e acompanhantes" (JESUS, 2010, p.82), ou seja, sua complexidade não implica em qualquer redução de sua importância.

\section{CONSIDERAÇÕES FINAIS}

O contexto da pedagogia hospitalar é complexo em demasia para uma lei tão direta quanto a de que a Educação é um direito fundamental de todos os cidadãos. É preciso considerar todas as dificuldades e não, como geralmente se posicionam as autoridades, apenas olhar os problemas de fora. Todas as complicações que o grupo imaginava encontrar no meio hospitalar foram certamente notadas. Porém, percebeu-se uma paixão pela educação em todos os envolvidos que foi surpreendente, que os faziam superar os limites. A metodologia qualitativa foi eficiente para captar essa paixão. Da mesma maneira, todas as questões encontradas nas bibliografias estudadas sobre a pedagogia hospitalar descreveram amplamente o cenário da importância da educação e os problemas que na prática nós verificamos.

Ao contrário de muitos estudantes de medicina que procuraram o enfermo para estudar a sua doença, este trabalho havia sido a primeira pesquisa realizada pelo curso de Pedagogia com o aluno que "desejava ver o que ele conseguia fazer e não o que ele não conseguia”. Isto evidencia a importância de pesquisas sobre a Pedagogia Hospitalar. Portanto, mais que chegar a um resultado, uma solução para o problema, o essencial dos trabalhos de pesquisa é questionar e expor situações até então pouco abordadas. Essa pesquisa, certamente, resultou em grande experiência tanto para os participantes do grupo, que se sentiram cada vez mais incentivados a investigar o mundo da educação e a lutar por uma melhor educação que atinja todos, como para os entrevistados, que sentiram que seus esforços pela educação foram reconhecidos, ou seja, não foram em vão.

Deixamos aqui para reflexão que "A educação é um direito de todos, por meio da educação podemos cultivar um cidadão ético competente, solidário, como seu semelhante [...]" (ANDRADE, 2010, p.124). Reconhecer que existem pessoas que se preocupam com os rumos da educação e dão para ela a devida relevância é um primeiro e grande passo para uma futura mudança. Essa mudança parte tanto das instituições hospitalares como, por exemplo, a que recebeu esse projeto, que devem mostrar interesse por projetos pedagógicos, assim como dos atuais professores e 
alunos no campo educacional e dos futuros profissionais da área pedagógica.

\section{REFERÊNCIAS}

[1] Andrade, J. C. De. Educação: um direito interrompido? in: MATOS, E. L. M. (Org.). Escolarização hospitalar: educação e saúde de mãos dadas para humanizar (2a ed.). Petrópolis: Vozes, 2010.

[2] Assis, W. De. Atendimento pedagógico-educacional em hospitais: da exclusão à inclusão social/escolar. Dissertação de mestrado, Universidade de São Paulo, São Paulo, SP, Brasil, 2009.

[3] Fontana, M. I.; Salamunes, N. L. C. Atendimento ao escolar hospitalizado - Smec. in: MATOS, E. L. M. (Org.). Escolarização hospitalar: educação e saúde de mãos dadas para humanizar (2a ed.). Petrópolis: Vozes, 2010.

[4] Jesus, V. B. G. De. Atuação do pedagogo em hospitais. in: MATOS, E. L. M. (Org.). Escolarização hospitalar: educação e saúde de mãos dadas para humanizar (2a ed.). Petrópolis: Vozes, 2010.

[5] Lima, L. F. De. Saberes necessários para a atuação em pedagogia hospitalar. Tese de Doutorado em Psicologia, Pontifícia Universidade Católica de São Paulo, São Paulo, 2010.

[6] Paula, E. M. A. T. De. Educação popular na pedagogia hospitalar: práticas e saberes em construção. In: $37^{a}$ Reunião Nacional da Anped, Florianópolis, 2015

[7] Rodacoski, G. C.; Forte, L. T. Prática pedagógica em complexo hospitalar. in: MATOS, E. L. M. (Org.). Escolarização hospitalar: educação e saúde de mãos dadas para humanizar (2a ed.). Petrópolis: Vozes, 2010.

[8] Torres, P. L., Matos, E. L. M.; Bortolozzi, J. M. Eurek@ Kids - Criatividade em contexto escolar e hospitalar. In: MATOS, E. L. M. (Org.). Escolarização hospitalar: educação e saúde de mãos dadas para humanizar (2a ed.). Petrópolis: Vozes, 2010.

[9] Trugilho, S. M. Classe hospitalar e a vivência do otimismo trágico: um sentido da escolaridade na vida da criança hospitalizada. Dissertação de mestrado, Universidade Federal do Espírito Santo, Vitória, ES, Brasil, 2003. [10] Verdi, C. A importância da literatura infantil no hospital. (2010). In: MATOS, E. L. M. (Org.). Escolarização hospitalar: educação e saúde de mãos dadas para humanizar (2a ed.). Petrópolis: Vozes, 2010. 


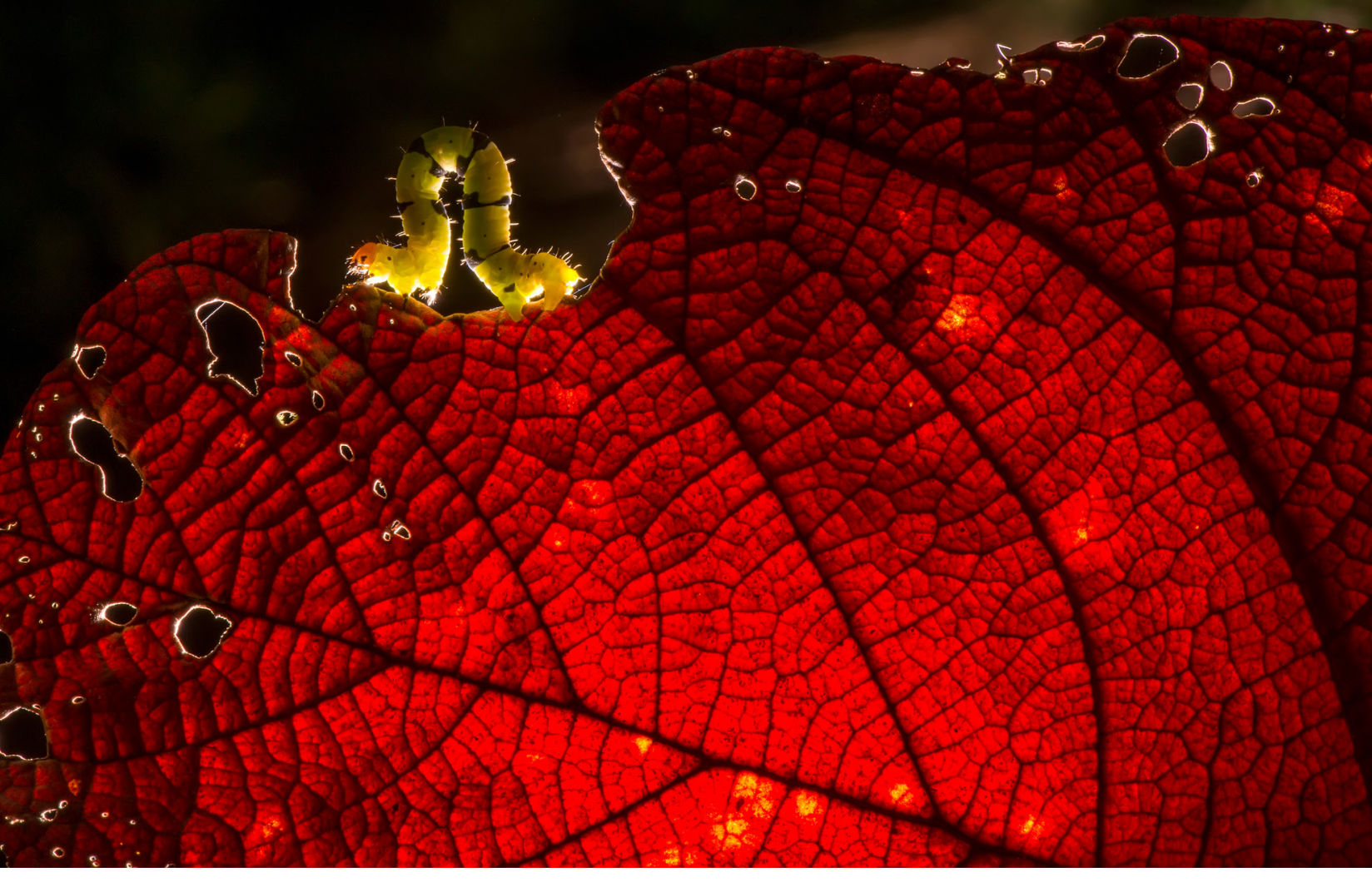

